\title{
IMPLEMENTASI SISTEM APLIKASI DAN METODE PEMBELAJARAN PAIKEM GEMBROT BERJAS (BERBASIS JARINGAN SOSIAL)
}

\author{
Rayung Wulan ${ }^{1}$, Eddy Saputra ${ }^{2}$, Nur Ali $^{3}$ \\ Program Studi Informatika Universitas Indraprasta PGRI \\ E-Mail: utha2578@gmail.com¹, poetra2149@gmail.com², Nurali7896@yahoo.com³
}

\begin{abstract}
Abstrak
Proses pembelajaran pada satuan pendidikan diselenggarakan secara interaktif, aspiratif, menyenangkan, menantang, memotivasi peserta didik untuk berpartisipasi aktif, serta memberikan ruang yang cukup untuk bagi prakarsa, kreativitas, dan kemandirian sesuai bakat, minat, dan perkembangan fisik, serta psikologis anak didik." Menjadikan tenaga pendidik semakin tertantang dalam mengelola kelas, dengan bantuan alat peraga pendekatan mengajar (approach to teaching) yang digunakan bersama yang digunakan bersama dengan banyak metode tertentu dan dengan berbagai media pengajaran yang disertai penataan kelas dan tempat duduk siswa sedemikian rupa sehingga proses pembelajaran menjadi aktif, inovatif, kreatif, efektif, dan menyenangkan. Dengan demikian, para siswa merasa tertarik dan mudah menyerap pengetahuan dan keterampilan yang diajarkan. Perkembangan teknologi informasi dan komunikasi saat ini memungkinkan PAIKEM GEMBROT BER JAS istilah BERJAS artinya berbasis jejaring sosial (Internet). Pada saat sekarang ini sudah begitu banyak infrastuktur Teknologi Informasi dan Komunikasi yang ada.dan masyarakat (termasuk peserta didik) sudah paham dengan teknologi dan dibutuhkan pengetahuan tambahan untuk mempergunakan Teknologi tersebut. Dengan bantuan tutorial berbasis jaringan sosial membuat tenaga pendidik lebih mudah dalam memeragakan langsung kepada peserta didik.
\end{abstract}

Kata Kunci: Sistem Aplikasi, Metode Pembelajaran, PAIKEM GEMBROT BERJAS

\begin{abstract}
The process of learning in the educational unit organized an interactive, aspirational, fun, challenging, motivating the students to actively participate and provide enough space to for innovation, creativity, and independence according talents, interests, and physical development, as well as psychological protégé. " making educators are increasingly challenged to manage the class, with the help of props teaching approach (approach to teaching) that is shared is used along with a lot of specific methods and with different teaching media that accompanied the arrangement of the classroom and the seating of students such that the learning process becomes active, innovative, creative, effective, and fun. Thus, the students were interested and easily absorb the knowledge and skills that are taught. The development of information and communication technology currently allows PAIKEM fat BER JAS term suits means-based social networking (Internet). At the present time has been so much infrastructure, Information and Communication Technology which none.And community (including students) are already familiar with the technology and knowledge needed extra to use the technology. With the help of social networks based tutorial educators make it easier to demonstrate directly to students.
\end{abstract}

Keywords: Application System, Learning Method, PAIKEM GEMBROT BERJAS

\section{Pendahuluan}

Guru merupakan tenaga kerja yang mempunyai tugas dan tanggung jawab kemanusiaan yang besar dan berkaitan dengan proses pendidikan bangsa ini menuju gerbang keberhasilan dalam melepaskan belenggu kebodohan, yang menuntut profesionalitas tinggi dalam proses pembelajaran disekolah. 
Mengacu pada Peraturan pemerintah no 19 tahun 2005 bab IV pasal 19 ayat 1, yang berbunyi: "Proses pembelajaran pada satuan pendidikan diselenggarakan secara interaktif, aspiratif, menyenangkan, menantang, memotivasi peserta didik untuk berpartisipasi aktif, serta memberikan ruang yang cukup untuk bagi prakarsa, kreativitas, dan kemandirian sesuai bakat, minat, dan perkembangan fisik, serta psikologis anak didik."

Berdasarkan peraturan pemerintah tersebut muncul istilah PAIKEM GEMBROT yaitu Pembelajaran Aktif, Inovatif, Kreatif, Efektif dan Menyenangkan sehingga pembelajaran menjadi Gembira dan Berbobot.PAIKEM dapat didefinisikan sebagai: pendekatan mengajar (approach to teaching) yang digunakan bersama dengan banyak metode tertentu dan dengan berbagai media pengajaran yang disertai penataan kelas dan tempat duduk siswa sedemikian rupa sehingga proses pembelajaran menjadi aktif, inovatif, kreatif, efektif, dan menyenangkan. Dengan demikian, para siswa merasa tertarik dan mudah menyerap pengetahuan dan keterampilan yang diajarkan.

Melalui kompetensi profesionalnya, seorang guru dituntut mampu mewujudkan proses belajar mengajar yang maksimal agar bisa efektif mencapai tujuan materi yang disampaikan, selain itu guru juga harus bisa memancing siswa kreatif \& aktif dalam pembelajaran. Semua ini terangkum dalam program PAIKEM GEMBROT yang dicetuskan para ahli.

PAKEM adalah Pembelajaran Aktif, Kreatif, Efektif dan Menyenangkan. Disamping metodologi pembelajaran dengan nama atau sebutan "PAKEM", muncul pula nama yang dikeluarkan dengan sebutan "PAIKEM GEMBROT" dengan kepanjangan Pembelajaran Aktif, Inovatif, Kreatif, Efektif, Menyenangkan, Gembira dan Berbobot. Guru dapat menyajikan dengan atraktif/menarik dengan hasil terukur sesuai yang diharapkan siswa (orang) belajar secara aktif . Seiring dengan berkembangnya teknologi informasi cara guru dalam mentransformasikan bidang ilmunya menjadi kretif dengan memanfaatkan teknologi agar siswa menjadi cepat dalam menerima materi yang disampaikan. Saat ini PAIKEM GEMBROT menambah jalurnya melalui jalur aplikasi jaringan sosial agar mempermudah proses pembelajaran. Sehingga menjadi kesatuan yang berbasis aplikasi atau dengan kata lain metode pembelajaran PAIKEM GEMBROT BERJAS yaitu Pembelajaran Aktif, Inovatif, Kreatif, Efektif, Menyenangkan, Gembira dan Berbobot Berbasis Jaringan Sosial.

Perkembangan teknologi informasi dan komunikasi saat ini memungkinkan PAIKEM GEMBROT BER JAS istilah BERJAS artinya berbasis jejaring sosial (Internet), begitu banyak infrastuktur Teknologi Informasi dan Komunikasi yang ada dan masyarakat (termasuk peserta didik) sudah beradaptasi dengan teknologi, yang menjadi dasar dalam proses pembelajaran.MetodePAIKEM GEMBROT BER JAS istilah BERJAS artinya berbasis jejaring sosial (Internet) dianggap mampu untuk mengatasi dan mempermudah guru dan siswa dalam menerapkan sistem aplikasi berbasis jaringan sosial.

\section{Tinjauan Pustaka}

PAIKEM GEMBROT BERJAS ( Berbasis Jaringan Sosial ) sebagai model pembelajaran yang termasuk salah satu tipe/jenis model pembelajaran terpadu. Istilah PAIKEM GEMBROT BERJAS (Berbasis Jaringan Sosial ) pada dasarnya adalah model pembelajaran terpadu yang menggunakan tema untuk mengaitkan beberapa mata pelajaran sehingga dapat memberikan pengalaman bermakna kepada peserta didik, Khoiru Ahmadi (2011).

Fase PAIKEM GEMBROT pada dasarnya mengikuti langkah-langkah (sintak) pembelajaran terpadu. Secara umum sintak tersebut mengikuti tahap-tahap yang dilalui dalam setiap model pembelajaran yang meliputi 3 (tiga) tahap yaitu: 
Pertama, Tahap Perancanaan. Pada tahap ini hal-hal yang dilakukan oleh guru adalah menentukan kompetensi dasar dan menentukan indikator; dan hasil belajar.

Kedua, Tahap Pelaksanaan yang meliputi sub tahap: (I) Proses Pembelajaran oleh guru. Adapun langkah yang ditempuh guru antara lain:

1. Menyampaikan konsep pendukung yang harus dilakukan siswa

2. Menyampaikan konsep-konsep pokok yang akan dikuasai oleh siswa

3. Menyampaikan keterampilan proses yang akan dikembangkan

4. Menyampaikan alat dan bahan yang dibutuhkan, dan

5. Menyampaikan pertnyaan kunci. (II) Tahap Manajemen yang meliputi langkahlangkah: 1. Pengelolaan kelas, dimana kelas dibagi dalam beberapa kelompok; 2. Kegiatan proses; 3. Kegiatan pencacatan data, 4. Penerapan data yang didapat,Khoiru Ahmadi (2011).

Ketiga, Tahap Evaluasi, yang meliputi:

1. Evaluasi Proses, adapun hal-hal yang menjadi perhatian dalam evaluasi proses terdiri dari:

a. Ketetapan hasil pengamatan

b. Ketepatan penyusunan alat dan bahan, dan

c. Ketetapan menganalisis data

2. Evaluasi hasil, yaitu pengusaan konsep-konsep sesuai indikator yang telah ditetapkan.

3. Evaluasi psikomotorik, yaitu penguasaan penggunaan alat ukur.

Agar siswa dapat berhasil baik dalam belajar maka dia harus terlibat aktif dalam aspek mental dan fisiknya. Menurut Taslimuharrom (2008) dalam Syah dan Kariadinata (2009: 1415), sebuah proses belajar dikatakan aktif (active learning) apabila mengandung:

1. Keterlekatan pada tugas (Commitment)

Dalam hal ini, materi, metode, dan strategi pembelajaran hendaknya bermanfaat bagi siswa dan guru (meaningful), sesuai dengan kebutuhan siswa (relevant), dan bersifat/memiliki keterkaitan dengan kepentingan pribadi (personal).

2. Tanggung jawab (Responsibility)

Dalam hal ini, sebuah proses belajar perlu memberikan wewenang kepada siswa untuk berpikir kritis secara bertanggung jawab, sedangkan guru lebih banyak mendengar dan menghormati ide-ide siswa, serta memberikan pilihan dan peluang kepada siswa untuk mengambil keputusan sendiri.

3. Motivasi (Motivation)

Motivasi belajar siswa akan meningkat apabila ditunjang oleh pendekatan yang lebih berpusat pada siswa (student centered learning).

Guru mendorong siswa untuk aktif mencari, menemukan dan memecahkan masalahnya sendiri. Ia tidak hanya menyuapi murid, juga tidak seperti orang yang menuangkan air ke dalam ember.

1. Inovatif, memunculkan hal-hal baru dari pengalaman siswa yang dikontruksikan dengan materi pembelajaran. Guru harus dapat memfasilitasi siswa dalam memunculkan daya inovatif.

2. Kreatif dapat diartikan: menginginkan adanya perubahan yang baru, ingin mengadakan motivasi, mempunyai banyak cara untuk melakukan sesuatu, tidak cepat putus asa, tidak mudah puas dengan hasil kerja dan selalu ingin berbuat terus, menumbuhkan motivasi, percaya diri dan kritis serta mempunyai banyak cara.

Kriteria Kreatif :

1. Berpikir kritis

2. Memecahkan masalah secara konstruktif

3. Ide/ gagasan yang berbeda

4. Berfikir konvergen (pemecahan masalah yang "benar" atau "terbaik"). 
5. Berfikir divergen (beragam alternative pemecahan masalah)

6. Fleksibelitas dalam berpikir (melihat dari berbagai sudut pandang)

7. Berfikir terbuka

Efektif dapat diartikan: mamanfaatkan alat peraga yang ada di sekitar, diajak ke sumber belajar, melakukan observasi, memanfaatkan waktu yang ada, mengoptimalkan panca indera dan mengatur strategi pembelajaran.

Kriteria Efektif:

Ketercapaian target hasil belajar, dapat berupa:

1. Siswa menguasai konsep

2. Siswa mampu mengaplikasikan konsep pada masalah sederhana

3. Siswa menghasilkan produk tertentu

4. Siswa termotivasi untuk giat belajar

5. Menyenangkan dapat diartikan: penampilan guru yang menarik, suasana belajar tidak searah, kaya dengan metode, desain kelas yang tidak membosankan (enjoy learning), belajar sambil bermain dan bernyanyi, hasil belajar anak dipajang di kelas, didekatkan ke alam nyata, ada penghargaan bagi yang berprestasi.

Kriteria Menyenangkan:

Pembelajaran berlangsung secara:

1. Interaktif

2. Dinamik

3. Menarik

4. Menggembirakan

5. Atraktif

6. Menimbulkan inspirasi

PAIKEM GEMBROT menyediakan keluasan dan kedalaman implementasi kurikulum, menawarkan kesempatan yang sangat banyak pada siswa untuk memunculkan dinamika dalam pendidikan. PAIKEM GEMBROT BERJAS adalah epitom dari seluruh bahasa pembelajaran yang memfasilitasi siswa untuk secara produktif menjawab pertanyaan yang dimunculkan sendiri dan memuaskan rasa ingin tahu dengan penghayatan secara alamiah tentang dunia disekitar mereka.

Paikem gembrot sebagai model pembelajaran termasuk salah satu tipe/jenis daripada model pembelajaran terpadu. Istilah PAIKEM GEMBROT BERJAS pada dasarnya adalah model pembelajaran terpadu yang menggunakan tema untuk mengaitkan beberapa mata pelajaran sehingga dapat memberikan pengalaman bermakna kepada siswa (Trianto dalam Depdiknas, 2006: 5).

Menurut Jean Piaget (Nur dalam Iif Khoiru \& Sofan, 2011: 47), seorang anak maju melalui empat tahap perkembangan kognitif, antara lahir dan dewasa, yaitu: tahap sensorimotor, pra operasional, operasi kongkrit, dan operasi formal. Pola perilaku atau berfikir yang digunakan anank dan orang dewasa dalam menangani obyek- obyek di dunia disebut skemata. Selanjutnya menurut Piaget bahwa anak membangun sendiri skemata-skemata dari pengalaman sendiri dengan lingkungannya. Di sini peran guru adalah sebagai fasilitator dan bukan sebagai pemberi informasi. Guru perlu menciptakan lingkungan yang kondusif bagi para siswanya. (Hadisubroto dalam Iif Khoiru \& Sofan, 2011: 49).

Jelas teori piaget tersebut menegaskan bahwa guru harus mampu menciptakan keadaan pembelajar yang mampu belajar mandiri. Artinya guru tidak sepenuhnya mengajarkan suatu bahan ajar kepada pembelajar, tetapi guru dapat membangun pembelajar yang mampu belajar dan terlibat aktif dalam belajar dan metode pembelajaran PAIKEM GEMBROT BERJAS (Pembelajaran Aktif, Inovatif, Kreatif, Efektif, Menyenangkang Gembira dan Berbobot Berbasis Jaringan Sosial) saat ini sangat diminati oleh siswa dan guru. 


\section{Metodologi Penelitian}

Metode penelitian yang digunakan dalam pelaksanaan kegiatan penelitian ini adalah approach to teachingmetode ini dengan pendekatan pengajaran dan instrumentasi penelitian yang digunakan untuk meneliti pada kondisi obyek yang terjadi, di mana peneliti membuat dan memperagakan aplikasi sebagai instrument kunci, teknik pengumpulan data dilakukan secara gabungan, analisis data yang bersifat induktif, dan hasil penelitian kualitatif lebih menekankan makna, yang terbagi ke dalam dua tahap, yakni pelatihan dan instrumentasi.

1. Pelatihan

Memberikan pelatihan kepada seluruh peserta dengan menyampaikan materi tentang METODE PAIKEM GEMBROT BERJAS. Kegiatan pelatihan ini dilakukan dengan memberikan pengetahuan mengenai metode pembelajaran PAIKEM GEMBROT BERJAS.

2. Instrumentasi

Setelah melakukan pelatihan, dilanjutkan dengan melakukan pendampingan kepada peserta dalam rangka memberikan informasi tentang cara membuat dan mengakses Aplikasi PAIKEM GEMBROT BERJAS.

Peran instrumentasi-experiment dalam area penelitian sosial ini, khususnya dalam area pendidikan adalah ketika melihat manusia sebagai objek penelitian yang memiliki karakterkarakter tertentu yang jelas berbeda satu sama lain dan sulit untuk diukur presentasikan hanya dengan angka-angka. Hal terpenting dari nilai instrumentasi experiment adalah bagaimana hasil analisa kuantiatif tersebut dapat menjadi informasi penting yang mendukung data kualitatif atau sebaliknya dalam desain mixed approach (Tashakkori, A., 2009).

Adapun skema pelaksanaan kegiatan Penelitian ini adalah sebagai berikut:

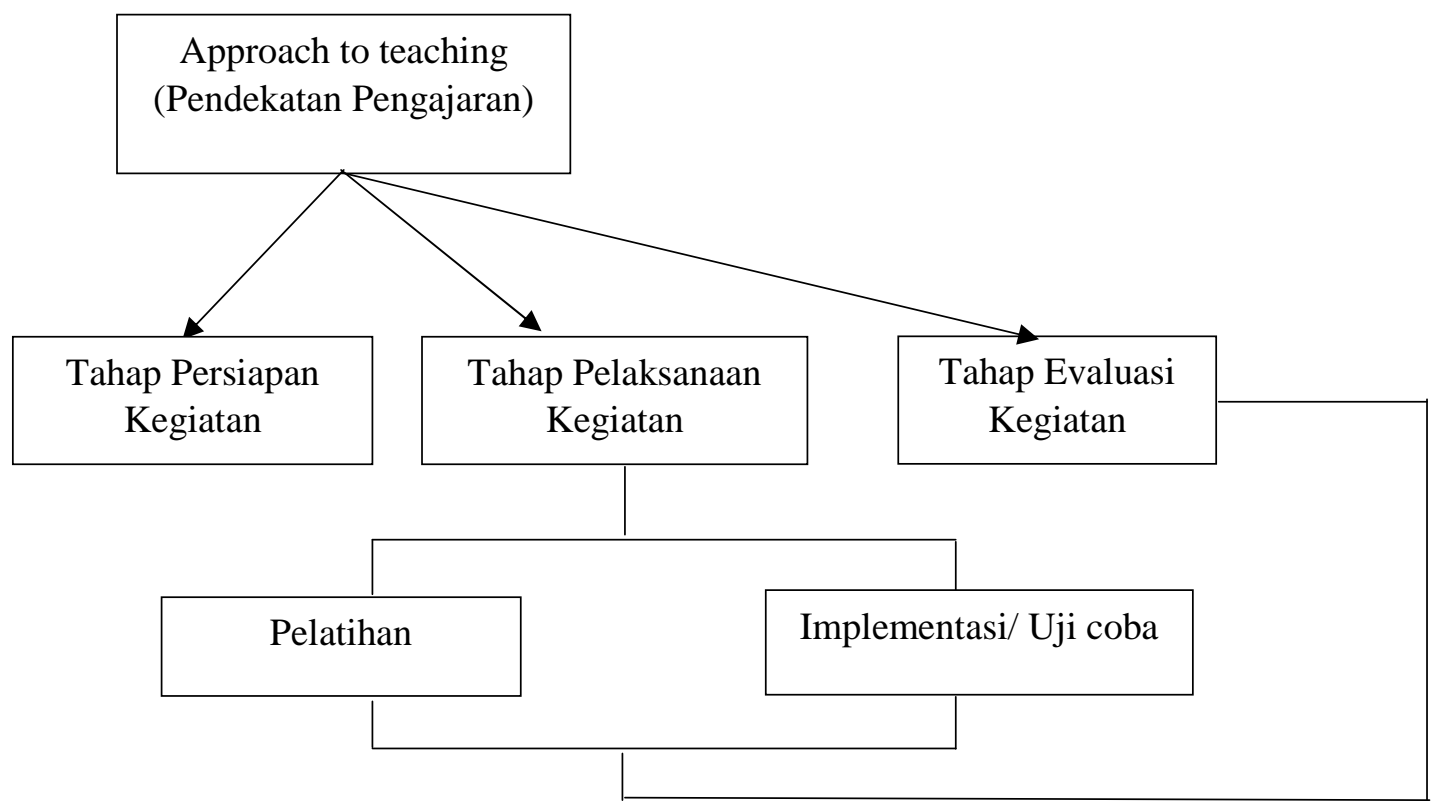

Gambar 1.InstrumentasiExperimen

(Sumber: Tashakkori, 2009) 


\section{Hasil dan Pembahasan}

Analisis Perancangan Metode Pembelajaran PAIKEM GEMBROT BERJAS (Pembelajaran Aktif, Inovatif, Kreatif, Efektif, Menyenangkang Gembira dan Berbobot Berbasis Jaringan Sosial)

Perancangan merupakan strategi atau suatu kegiatan yang bertujuan untuk mendesain sistem baru yang dapat memecahkan masalah yang dihadapi untuk menghasilkan tampilan desain yang sesuai dengan kriteria. Metode Pembelajaran PAIKEM GEMBROT BERJAS (Pembelajaran Aktif, Inovatif, Kreatif, Efektif, Menyenangkang Gembira dan Berbobot Berbasis Jaringan Sosial) di buat untuk mempermudah tenaga pengajar dalam mengaplikasikan mata pelajaran yang mudah dimengerti oleh peserta didik.

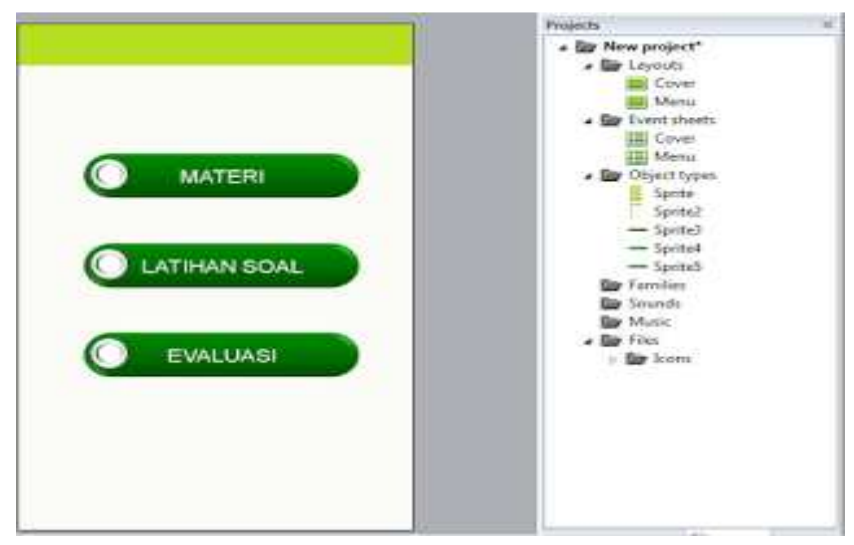

Gambar 2.Rancangan Tutorial berbasis jaringan sosial (Sumber: Tutorial Penulis ,2016)

Rancangan pada dasarnya merupakan cara atau suatu kegiatan mempunyai tujuandalam rangkamempermudah sistem baru yang dapat menyelesaikan masalah yang dihadapi untuk memperolehcara yang tepat dan mudah dimengerti. Cara menggunakan atau menambah mata pelajaran yang akan dimuat dalam metode pembelajaran PAIKEM GEMBROT BERJAS (Pembelajaran Aktif, Inovatif, Kreatif, Efektif, Menyenangkang Gembira dan Berbobot Berbasis Jaringan Sosial) dapat dilihat dibawah ini.

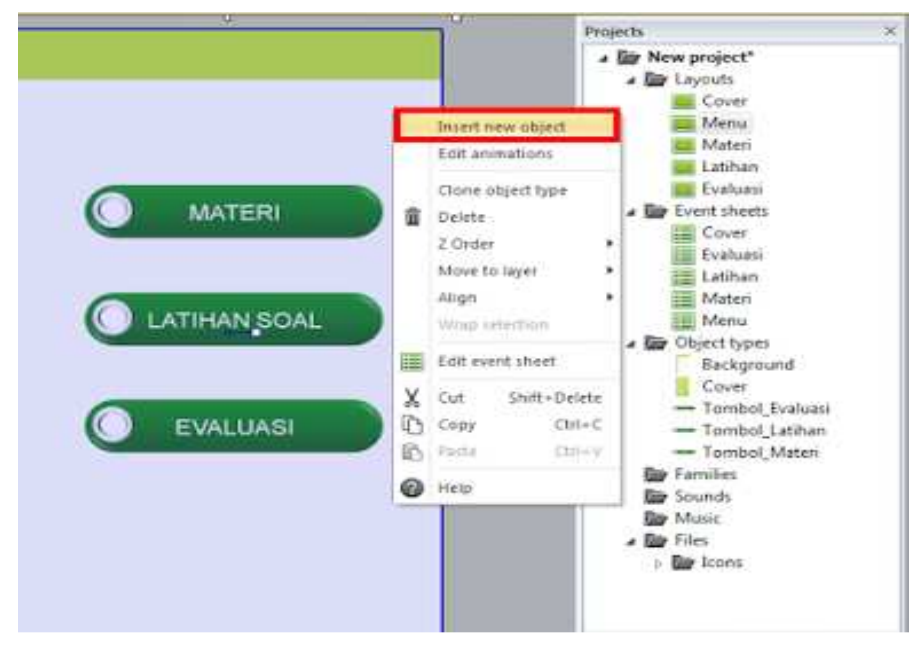

Gambar 3. Menambah Mata Pelajaran yang disajikan (Sumber: Tutorial Penulis, 2016) 
Dengan analisis data tersebut, maka dapat diimpelentasikan dengan penerapan PAIKEM Gembrot dapat dijadikan alternatif pembelajaran untuk meningkatkan hasil belajar siswa serta menambah wawasan bagi tenaga pendidik.

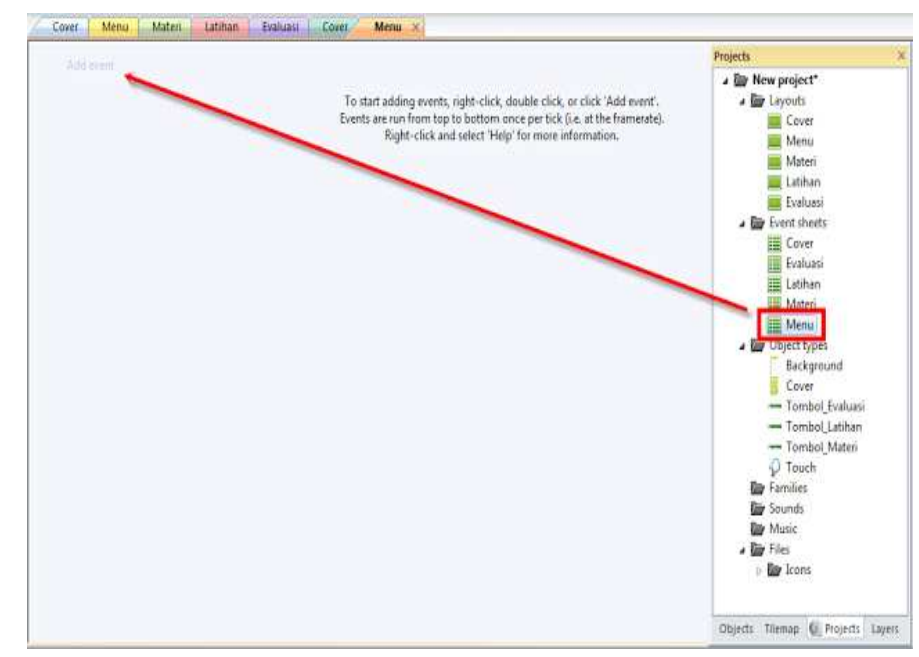

Gambar 4. Tampilan Menu Jenis Mata Pelajaran (Sumber:Tutorial Penulis, 2016)

\section{Analisis Implementasi Penerapan Sistem Aplikasi PAIKEM GEMBROT BERJAS (Pembelajaran Aktif, Inovatif, Kreatif, Efektif, Menyenangkang Gembira dan Berbobot Berbasis Jaringan Sosial)}

Implementasi penerapan sistem aplikasi merupakan tahap dari serangkaian proses, implementasi sistem merupakan bagian dari pengembangan sistem aplikasi hanya saja Implementasi sistem (system implementation) Merupakan kegiatan memperoleh dan mengintegrasikan sumber daya fisik dan konseptual yang menghasilkan suatu sistem yang bekerja. Tahap implementasi sistem (system implementation) adalah tahap meletakkan sistem supaya siap dioperasikan.

Pelaksanaan Aktivitas-aktivitas Implementasi, mencakup pelaksanaan actual rencana perancangan, yang meliputi :

1. Pemilihan

2. Pelatihan personal

3. Pemasangan (instalasi)

4. Perancangan sistem terinci

5. Penulisan dan pengujian

6. Pengujian sistem

7. Pengembangan standar

8. Dokumentasi

9. Konversi file

Dalam melaksanakan rencana implementasi, harus dilakukan pengukuran-pengukuran tertentu untuk membantu transisi dan meyakinkan hasil implementasi tersebut. Aspek penting lainnya dalam tahap pelaksanaan adalah implementasi adalah program dapat berjalan sesuai dengan desain yang direncanakan. 


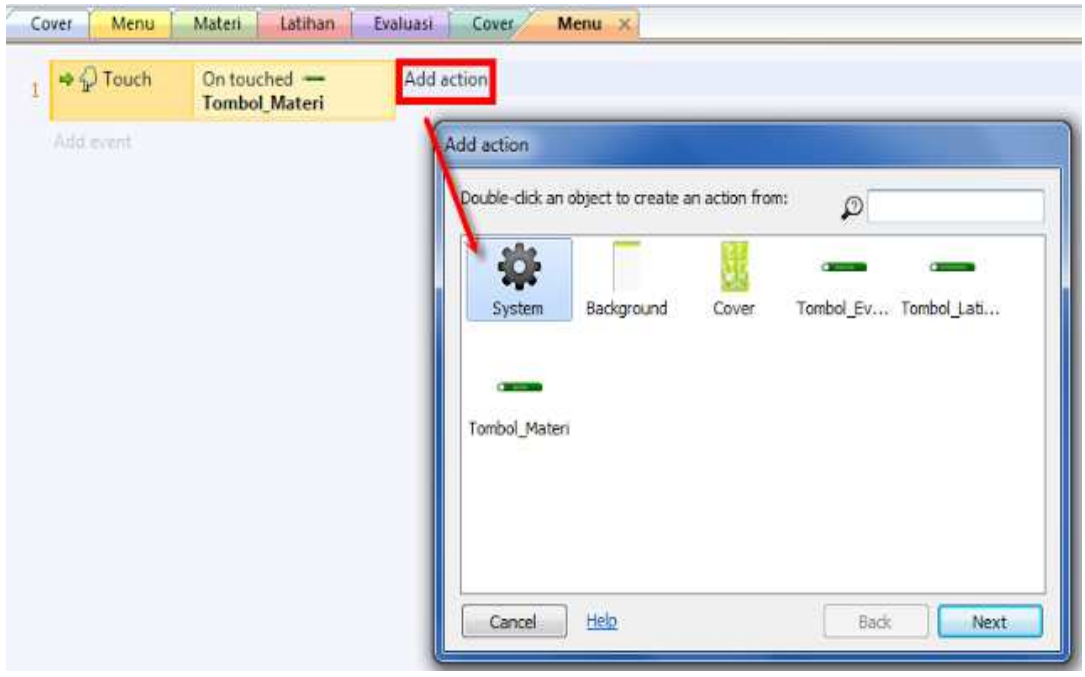

Gambar 5. Hasil Desain Tampilan sistem aplikasi (Sumber: Tutorial Penulis, 2016)

Analisa Sistem Jika tahapan pengumpulan data dilakukan dengan melibatkan klien atau pengguna sistem informasi, maka mulai dari tahapan analisa lebih banyak dilakukan oleh pihak pengembang sendiri. Analisa terhadap sistem yang sedang berjalan dan sistem yang akan dikembangkan. Mendefinisikan objek-objek yang terlibat dalam sistem dan batasan sistem.

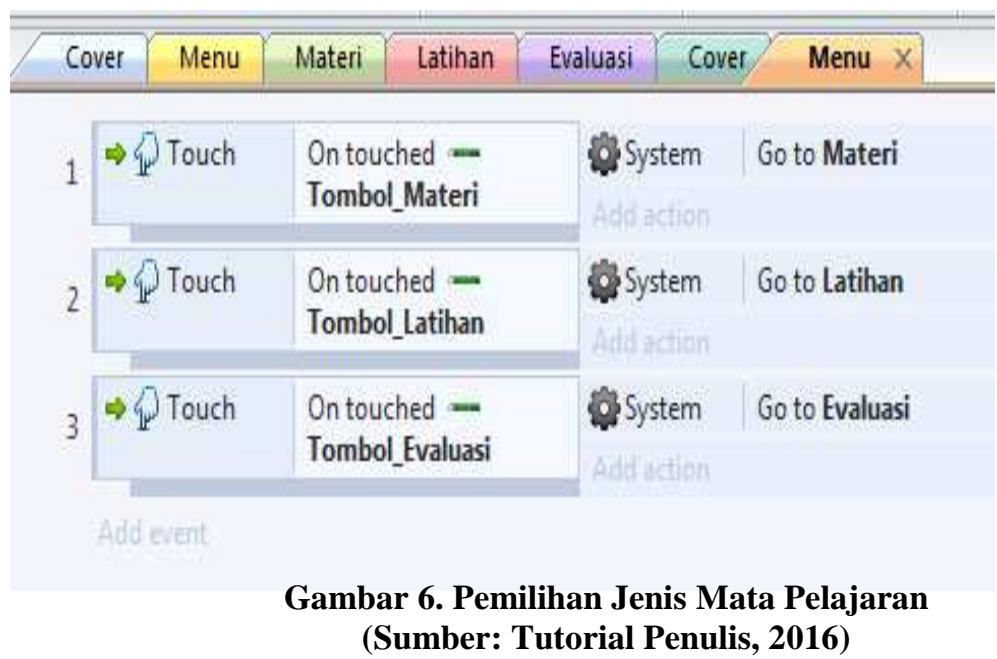

Dengan cara yang sama berilah navigasi pada Tombol_Latihan dan Tombol_Evaluasi sehingga pada event sheet "Menu" terdapat tiga event sebagai berikut. Disini bisa ditambahkan macam macam contoh soal atau latihan latihan yang diperlukan sehingga pengguna dapat membuka hanya yang ada didalam aplikasi tersebut.

Makna event tersebut yaitu, (1) ketika Tombol_Materi pada layout "Menu" disentuh maka akan beralih ke Layout "Materi", (2) ketika Tombol_Latihan pada layout "Menu" disentuh maka akan beralih ke Layout "Latihan", dan (3) ketika Tombol_Evaluasi pada layout "Menu" disentuh maka akan beralih ke Layout "Evaluasi".

Selain itu kita juga bisa menambahkan lebih dari satu layout materi untuk menuliskan konten materi secara lebih lengkap. Untuk menulis konten materi silahkan pilih layout Materi. Materi berupa teks dituliskan dengan klik kanan pada layout Materi kemudian pilih Insert new object selanjutnya pilih Text. 


\section{Simpulan dan Saran}

\section{Simpulan}

Berdasarkan hasil pemaparan diatassistemaplikasi dan metode PAIKEM GEMBROT BERJAS (BERBASIS JARINGAN SOSIALdapat mempermudah tenaga pengajar dan peserta didik, metode tersebut mampu menggunakan Aplikasi Jejaring Sosial sebagai metode pembelajaran yang sesuai dengan PAIKEM GEMBROT BERJAS. Sehingga para guru diharapkan dapat ikut meningkatkan kualitas tenaga pendidik dilingkungan sekolah.

Dengan paham akan metode pembelajaran PAIKEM GEMBROT BERJAS, peserta didik menjadi senang akan sesuatu hal yang baru dan dapat mudah memahami mata pelajaran.

Saran

Berdasarkan simpulan sebelumnya, diberikan saran-saran sebagai berikut:

1. Sekolah diharapkan dapat meningkatkan kapasitas ketersediaan akses internet yang lebih besar sehingga dapat menjangkau seluruh wilayah yang ada di sekolah.

2. Pengguna diharapakan dapat meluangkan waktu untuk terus menggali informasi metode pembelajaran berbasis aplikasi PAIKEM GEMBROT BERJAS.

3. Pengguna dapat mengajak dan memberikan informasi pentingnya metode pembelajaran berbasis aplikasi, karena memudahkan guru dalam metode pembelajaran dan menyenangkan siswa dalam proses belajar dan pembelajaran.

4. Pengguna dapat bekerja sama dengan pihak Sekolah dan orang tua wali murid untuk memantau perkembangan siswa dengan aplikasi PAIKEM GEMBROT BERJAS.

\section{Daftar Pustaka}

Iif Khoiru Ahmadi \& Sofan Amri. (2011). Paikem Gembrot, Jakarta : Prestasi Pustaka.

Trianto. (2006). Model Pembelajaran Terpadu dalam Teori dan Praktik, Jakarta : Prestasi Pustaka.

Taslimuharom. (2008). Metode Paikem Gembrot., Jakarta : Prestasi Pustaka.

Ramadhan. (2008). Penerapan PAIKEM dalam pembelajaran, Jakarta : Balai Pustaka

Mashudi Wahyu.(2016). Revolusi Mengajar: Pembelajaran Akrif, Kreatif, Efektif, Menyenangkan, Jakarta : Angkasa

Khoiru Ahmadi dan Sofan Amri. (2011).PAIKEM GEMBROT (Sebuah Analisis Teoritis, Konseptual, dan Praktis),Jakarta: Prestasi Pustaka.

Mulyono, H. (2012). Melihat Quasi Experiment dari 2 sisi. Jakarta : Balai Pustaka

Tashakkori, A.(2009). Instrumentasi-Experiment Penelitian. Jakarta : Prestasi Pustaka 